\title{
Migração infantil: aspectos e implicações para crianças e adolescentes
}

\begin{abstract}
Resumo:
O artigo visa retratar o fenômeno da migração atual pelo mundo e os desafios que os migrantes internacionais têm enfrentado, identificando as características do processo de migração infantil e destacando a situação de vulnerabilidade que crianças e adolescentes estão sujeitos, num mundo cada vez mais hostil, e repleto de barreiras e preconceitos. Para muitas pessoas, a migração é a única maneira de escapar da insegurança e opressão que sofrem em seus países. Contudo, para as crianças e adolescentes migrantes a situação é mais delicada, pois são, em geral, mais suscetíveis à discriminação, exploração, xenofobia e ao tráfico de seres humanos. Nesse contexto, destaca-se a importância da educação e o papel fundamental da escola para que esse grupo se integre de maneira adequada a nova sociedade, pois normalmente estão em situação de vulnerabilidade, principalmente, devido à barreira linguística e às condições de vida precárias em que se encontram, que podem influenciar de maneira significativa os processos de desenvolvimento social e educacional.
\end{abstract}

\section{Palavras-Chave:}

Migração infantil. Vulnerabilidade. Educação. Escola.

\section{Child Migration: aspects and implications for children and teenagers}

\begin{abstract}
:
The article aims to portray the current migration phenomenon around the world and the challenges that international migrants have faced, identifying the characteristics of the child migration process and highlighting the situation of vulnerability to which children are subjected. and adolescents, in an increasingly hostile way. world, and full of barriers and prejudices. For many people, migration is the only way to escape the insecurity and oppression they experience in their countries. However, for migrant children and adolescents the situation is more delicate, since they are, in general, more susceptible to discrimination, exploitation, xenophobia and human trafficking. In this context, the importance of education and the fundamental role of the school are highlighted so that this group is
\end{abstract}

1 Doutora em Ciências Sociais, Mestra em Economia Política pela Pontifícia Universidade Católica de São Paulo - PUC-SP. Pesquisadora que atua nas áreas de Estudos Urbanos e Migrações. E-mail: luciafabiano@uol.com.br ORCID iD: https://orcid. org/0000-0001-9675-5106 
adequately integrated into the new society, since they are usually in a vulnerable situation, mainly due to the language barrier and precarious living conditions in which they find themselves, which can significantly influence the processes of social and educational development.

\section{Keywords:}

Child migration. Vulnerability. Education. School.

\section{Migración infantil: aspectos e implicaciones para la niñez y la adolescência}

\section{Resumen:}

El artículo tiene como objetivo retratar el fenómeno de la migración actual en todo el mundo y los desafíos que han enfrentado los migrantes internacionales, identificando las características del proceso migratorio infantil y destacando la situación de vulnerabilidad a la que están sujetos los niños, niñas y adolescentes, de una forma cada vez más hostil. mundo, y lleno de barreras y prejuicios. Para muchas personas, la migración es la única forma de escapar de la inseguridad y la opresión que experimentan en sus países. Sin embargo, para los niños, niñas y adolescentes migrantes la situación es más delicada, ya que son, en general, m\&aacute ; s susceptibles a la discriminación, la xenofobia, la explotación, y la trata de personas. En este contexto, se destaca la importancia de la educación y el papel fundamental de la escuela para que este grupo se integre adecuadamente a la nueva sociedad, ya que normalmente se encuentran en una situación de vulnerabilidad, principalmente por la barrera del idioma y las precarias condiciones de vida en que se encuentran, que pueden influir significativamente en los procesos de desarrollo social y educativo.

\section{Palabras clave:}

Migración infantil. Vulnerabilidad. Educación. Colegio.

\section{Introdução}

Os acontecimentos do século XXI têm afetado de maneira significativa o fenômeno da migração pelo mundo, colocando pertinentes questões em evidência, tais como: conflitos étnicos, terrorismo, fundamentalismos religiosos, contrabando de drogas e tráfico de pessoas, que se acentuaram demasiadamente neste século.

A migração internacional ${ }^{2}$ é um fenômeno complexo que aborda uma multiplicidade de aspectos sociais, econômicos, políticos e de segurança que afetam a nossa vida cotidiana num mundo cada vez mais interligado. Sendo assim, os novos desafios para as migrações internacionais no século XXI, como argumenta Baeninger (2015, p. 17), implicam necessárias revisões conceituais acerca das novas mobilidades, modalidades e explicações acerca desse fenômeno social. Nesse sentido, a autora cita Bakewell (2010) cuja abordagem enfatiza que a relação entre migração e mudança social passa a compor a agenda de pesquisa para a compreensão dos fenômenos migratórios contemporâneos.

O contexto global atual tem alterado o caráter da migração internacional, principalmente no que se refere à livre circulação das pessoas, com fluxos que se manifestam hoje em diferentes direções do planeta. Apesar de países de alta renda ainda polarizarem esses fluxos, são observados

20 termo migração internacional corresponde aos movimentos de saída e chegada de pessoas (migrantes) entre países. É importante ressaltar que o termo pode ser subdividido em emigração (refere-se às pessoas que saem do país, que podemos chamar de emigrantes) e imigração (refere-se às pessoas que entram no país, chamados de imigrantes). 
novos centros de atração no hemisfério sul, como é o caso dos polos econômicos do Oriente Médio (Cingapura, Malásia, Taiwan, Coreia do Sul) e na África (Gabão e África do Sul). A América Latina e Caribe também apresentam crescimento da migração sul-sul entre e em direção aos vários países do continente.

Segundo estudos realizados pelo Observatório das Migrações da Unicamp (BAENINGER; FERNANDES, 2018), o pano de fundo desse movimento é a mobilidade do capital e da força de trabalho, potencializado pela intensificação no fechamento das fronteiras por países da Europa e Estados Unidos, que consequentemente modificou o rumo das migrações para os países do sul.

Tais evidências empíricas recentes somente demonstram a complexidade e a heterogeneidade da migração internacional neste século. E como coloca Patarra (2006, p. 9), o entendimento dos processos sociais envolvidos nos fluxos de pessoas entre os países, regiões e continentes envolvem fenômenos muito distintos, com grupos sociais e implicações diversas, que têm assumido características novas que interessa analisar e entender.

Essa população que migra não é somente formada por trabalhadores, mas por famílias, muitas vezes constituídas por crianças e jovens, que utilizam os serviços públicos: escolas, hospitais, parques, apoios sociais. Enfim, fazem parte das cidades e do seu cotidiano, demandando uma atenção especial e políticas públicas adequadas para sua integração às sociedades receptoras.

Partindo desse ponto de vista e de modo a tentar compreender dentro dos diversos aspectos que norteiam o processo migratório atual, o presente texto tem por objetivo discorrer sobre a situação migratória no mundo, mas especialmente sobre as condições às quais crianças e adolescentes estão submetidos nesse processo, pois geralmente esse grupo é invisibilizado pela figura do "trabalhador migrante", ocupando um espaço secundário e desconsiderando que são agentes portadores de direitos com seus próprios enfrentamentos. Entende-se que uma criança migrante condensa uma dupla situação de vulnerabilidade, relativas à idade e condição migratória, que demanda uma proteção específica e adequada de seus direitos por parte dos Estados (de origem, trânsito e destino) e de outros atores envolvidos.

Sendo assim, este artigo se divide no sentido de apresentar o processo migratório atual, mostrando aspectos específicos da migração infantil pelo mundo e os desafios a que crianças e adolescentes estão sujeitos, que vão muito além do processo conturbado de trânsito até o destino, mas surgem também após serem acolhidas pelos países receptores, esbarrando na dificuldade para acessar o sistema educacional e no desafio de adaptação enfrentados dentro e fora da escola, até serem, de fato, integrados de forma adequada na sociedade.

\section{A crise migratória do século XXI}

No que diz respeito à crise migratória na atualidade, pode-se observar que a discrepância crescente entre os níveis de desenvolvimento e as estruturas demográficas dos países ricos e pobres gera desigualdades entre os Estados, levando a uma situação política, econômica e social conflituosa. Sendo assim, tem se intensificado a pobreza, os conflitos violentos e os ataques ao meio ambiente, que induzem ao deslocamento das populações na busca de melhores condições de vida e, principalmente, de sobrevivência, gerando um número cada vez maior de pessoas em trânsito pelo mundo.

Segundo informações do relatório do Department of Economic and Social Affairs, Population Division, United Nations ${ }^{3}$ (2017), o número de migrantes internacionais tem crescido rapidamente nos últimos anos, atingindo 258 milhões em 2017, em comparação com 220 milhões em 2010, e 173 milhões em 2000, um crescimento de 49,13\% em 17 anos. Mais de 60\% vivem na Ásia

3 Departamento de Assuntos Econômicos e Sociais da ONU. 
(79,6 milhões) ou na Europa (77,8 milhões), seguidos pela América do Norte com (57,7 milhões), África (24,6 milhões), América Latina e Caribe (9,5 milhões) e Oceania (8,4 milhões). As mulheres compõem atualmente $48 \%$ desta população.

Em 2017, cerca de 67\% viviam em apenas vinte países. Os países de alta renda absorveram a maior parte desse crescimento recente, ganhando 64 milhões dos 85 milhões de migrantes adicionados em todo o mundo entre 2000 e 2017.

O número total de refugiados ${ }^{4}$ e requerentes de asilo ${ }^{5}$ no mundo em 2016 foi estimado em 25,4 milhões. A Turquia tem a maior população de refugiados em todo o mundo, com 3,1 milhões, Jordânia (2,9 milhões), Estado da Palestina (2,2 milhões), Líbano (1,6 milhões) e Paquistão (1,4 milhões).

A idade média em todo o mundo foi de 39 anos em 2017, um ligeiro aumento em relação ao ano 2000, que era de 38 anos. No entanto, em algumas regiões, essa população está se tornando cada vez mais jovem. Entre 2000 e 2017, a idade média declinou na Ásia, América Latina e Caribe, e Oceania.

De acordo com dados do Departamento de Assuntos Sociais e Econômicos da ONU (2017), a maioria dos migrantes está em idade de trabalho. Em 2017, 74\% tinham entre 20 e 64 anos e 12\% tinham mais de 65 anos. Referente às crianças e jovens pelo mundo, é estimado que tenhamos cerca de 14\% com idade até 19 anos o que representa cerca de 36,1 milhões de crianças e adolescentes, distribuídos entre 0-4 anos (3\%); 5-9 anos (3\%); 10-14 anos (4\%) e 15-19 (4\%).

Diariamente, somos bombardeados com notícias a respeito da quantidade de migrantes que tentam entrar nos países, colocando em risco suas vidas e sendo impedidos pelas guardas de fronteiras nacionais. As pessoas que se lançam nessa jornada o fazem por vários motivos e se utilizam de meios diferentes. Muitos procuram as vias legais, contudo, temos aqueles que estão igualmente dispostos a arriscar a vida para fugir da situação em que se encontram, como: repressão política, guerras, pobreza ou para se juntarem às suas famílias, para poderem ter acesso a trabalho, educação, moradia, saúde e outros serviços públicos.

Um dos principais destinos são os Estados Unidos que, além da Europa, apresentam dados alarmantes sobre as terríveis condições a que migrantes estão expostos. De acordo com a Patrulha Fronteiriça - US BORDER PATROL (2017), pelo menos 6.915 pessoas morreram tentando cruzar a fronteira entre os Estados Unidos e o México entre 1998 e 2016. Já os dados da Organização Internacional das Nações Unidas para as Migrações - IOM (2017) apontam que somente entre 2014 e junho de 2017 foram registradas quase 2 mil mortes nas Américas, sendo que a maioria ocorreu na fronteira entre os dois países.

Os imigrantes irregulares evitam entrar em contato com as autoridades em áreas bem patrulhadas e são frequentemente obrigados a atravessar por locais perigosos como o deserto do Arizona e o Rio Grande. De acordo com a agência da Organização das Nações Unidas - ONU -, as principais causas de mortes citadas são: a exposição prolongada a ambientes extremos na região fronteiriça com temperaturas que atingem frequentemente $40^{\circ}$ Celsius, combinada com a dificuldade de levar assistência aos necessitados em áreas remotas.

Estima-se que pelo menos 60 mil migrantes faleceram entre 2000-2017 em todo o mundo. A travessia do Mar Mediterrâneo com destino à Europa é a jornada mais perigosa para os migrantes, sendo registrados 33 mil mortes ou desaparecimentos nesse período (IOM, 2017).

\footnotetext{
4 Refugiado é todo indivíduo que devido a fundados temores de perseguição por motivos de raça, religião, nacionalidade, grupo social ou opiniões políticas encontre-se fora de seu país de origem e não possa ou não queira acolher-se à proteção de tal país; ou que devido a grave e generalizada violação de direitos humanos, é obrigado a deixar seu país para buscar refúgio em outro (Lei n.o 9.474, de 22 de julho de 1997).

5 Requerente de asilo é aquele que solicita o reconhecimento do estatuto de refugiado e cujo pedido ainda não foi definitivamente avaliado. O conceito jurídico de asilo na América Latina é originário do Tratado de Direito Penal Internacional de Montevidéu, de 1889. O asilo pode ser de dois tipos: diplomático - quando o requerente está em país estrangeiro e pede asilo à embaixada do país que pretende se estabelecer, ou territorial - quando o requerente está em território nacional. Se concedido, o requerente estará ao abrigo do Estado, com as garantias devidas.
} 
O risco de morrer tem aumentado ao longo de algumas rotas migratórias, especialmente no Mar Mediterrâneo e nos Estados Unidos, onde o número de mortos continua a crescer, apesar dos dados relatarem uma quantidade menor de pessoas que tentam atravessar as fronteiras.

Ao mesmo tempo que os dados estão mais acessíveis, em algumas regiões do mundo eles permanecem incompletos, pois o número de mortes registradas inclui apenas aqueles com os quais os agentes lidam diretamente. Isso significa, na prática, que os dados reportados nacionalmente podem seriamente subestimar o número real de mortes.

As mudanças políticas e as restrições à entrada de estrangeiros com a intensificação do patrulhamento e imposições às operações de busca e resgate por parte de alguns Estados têm resultado em vários incidentes que decorrem no falecimento de milhares de pessoas. Isso significa que está cada vez mais difícil atravessar de maneira segura.

Diante desse quadro que se apresenta em pleno século XXI, e mesmo quando superadas as dificuldades da travessia de fronteiras, uma realidade dura se apresenta para suas vidas, principalmente em países localizados na Europa, Ásia e África, que obrigam os migrantes a permanecerem em imensos campos de "concentração", vivendo como prisioneiros em locais insalubres por longos períodos. Alguns campos chegam ao tamanho de cidades como o localizado em Dadaab no Quênia, que segundo o Alto Comissariado das Nações Unidas para Refugiados - ACNUR -, abriga mais de 400 mil pessoas (UNHCR, 2019).

Esses campos apresentam uma situação de inadequação nas condições de abrigo, saúde e nutrição, com crianças privadas de educação e serviços de apoio psicossocial. São identificados problemas de adaptação decorrentes de diferenças culturais, além de abuso da força de trabalho, assédio sexual contra as mulheres e meninas, prostituição forçada e casamentos não oficiais.

Diante de tais evidências observa-se que políticas migratórias restritivas dos países ricos falham por diferentes motivos, entre os quais a total incapacidade ou falta de vontade por parte desses países de regulamentar as suas relações. Pois como coloca Castles (2010, p. 16), os governantes enxergam a migração como um problema a ser resolvido, de preferência buscando formas para evitar que as pessoas não abandonem seu local de origem. Falta-lhes compreensão do processo como parte intrínseca do desenvolvimento humano, mediante o qual as pessoas respondem às oportunidades derivadas de fatores econômicos, políticos e ambientais. Da mesma forma, Bakewell (2010) enfatiza que esse discurso, o qual ele denomina "viés sedentário", constitui uma ameaça à prosperidade e à ordem pública dos países ricos e, portanto, os migrantes pobres devem ficar em seu próprio lugar.

Entretanto, Castles (2010, p. 17) destaca um aspecto relevante nesta discussão, sobre a necessidade dos países mais desenvolvidos necessitarem da mão de obra e, portanto, a expressão corrente do "viés sedentário" não é exatamente uma proibição dos movimentos sul-norte dos trabalhadores menos qualificados, mas sim a ideia de que a migração circular é uma situação "em que todos ganham" (win-win-win), tanto para os países que importam a mão de obra quanto para os países de origem e para os próprios migrantes. Sendo assim, o problema não é a migração em si, mas sim as condições de desigualdade sob as quais muitas das migrações se realizam, levando à marginalização e à exploração de muitos.

De qualquer forma, quando os governos tentam impedir a migração, um novo tipo de mercado entra em jogo, um mercado global, ligado às redes sociais que são desenvolvidas no processo migratório e organizado por agentes envolvidos no recrutamento de trabalhadores e funcionários de imigração, que lucram com o processo, seja legal ou não (CASTLES, 1997), aproveitando-se de pessoas que não têm os recursos econômicos nem os direitos políticos necessários para a livre circulação.

Sendo a migração parte do processo de transformação das estruturas e instituições, que nasce através de grandes mudanças nas relações sociais, econômicas e políticas globais (CASTLES, 2010), faz-se necessário o debate sobre as relações sociais e de identidade, que desempenham um 
papel-chave, praticamente em todos os países do Ocidente, levando ao surgimento de novas minorias étnicas, surgidas a partir desse processo nas últimas décadas.

Dessas minorias que surgem, temos as crianças e adolescentes que cada vez mais demandam atenção, tanto no debate acadêmico, como também na criação de novas políticas públicas que possam vir a acolhê-las de maneira satisfatória, pois se estamos falando dos diversos problemas que envolvem a migração tornando as pessoas tão desprotegidas e fragilizadas, quando tratamos especificamente deste grupo, podemos dizer que são duplamente mais vulneráveis, por estarem, na maioria das vezes, numa situação de submissão e dependência. Contudo, são agentes importantes nesse processo, pois são sujeitos portadores de direitos e necessitam ser visibilizados, para que suas demandas sejam atendidas.

\section{Aspectos e peculiaridades da migração infantil}

A migração infantil é hoje parte de um fenômeno contemporâneo que tem transformado o mundo em que vivemos. Atualmente, há milhões de crianças e adolescentes em movimento através das fronteiras internacionais, fugindo da violência, conflitos, catástrofes naturais e da pobreza, em busca de uma vida melhor.

Um marco importante que mudou a visão da mídia e do interesse público sobre essa questão ocorreu em 2 de setembro de 2015 quando o corpo de um menino de 3 anos de idade, foi encontrado em uma praia perto de Bodrum, na Turquia, depois que um barco transportando migrantes virou após a tentativa fracassada de alcançar a ilha grega de Kos.

O menino de Kobane, na Síria (cidade que ganhou notoriedade por ter sido palco de violentas batalhas entre militantes extremistas muçulmanos e forças curdas no início de 2015), morreu junto com seu irmão de 5 anos de idade e a mãe deles. Somente seu pai sobreviveu à tragédia. A família tinha como destino o Canadá, onde pretendiam juntar-se a alguns familiares que já viviam no país. Naquela época, o menino era apenas outra estatística, entre as milhares de pessoas conhecidas por terem morrido cruzando o Mar Mediterrâneo para a Europa.

Até 2015, o aumento constante no número de mortes relatadas na maioria dos países parecia ter pouco efeito sobre a opinião pública, mas a figura de uma criança com a face caída para baixo nas águas de uma praia despertou a atenção. A imagem foi compartilhada por centenas de milhões de pessoas em mídias sociais e estampou as primeiras páginas dos diversos jornais pelo mundo.

Tal fato levou ao ressurgimento do debate político sobre como enfrentar o atual desafio humanitário da migração e especialmente à questão da quantidade de crianças e adolescentes que migram acompanhadas ou desacompanhadas e que estão expostas a tantos perigos e o iminente risco de morte.

O relatório do Fundo das Nações Unidas para a Infância - UNICEF (2016a) Uprooted: The growing crisis for refugee and migrant children ${ }^{6}$ - apresenta dados que traçam um quadro sombrio sobre a vida e a situação de milhões de crianças e suas famílias afetadas por conflitos violentos e outras crises, que fazem parecer mais seguro arriscar tudo numa viagem perigosa do que permanecer em seu país de origem.

Segundo o relatório, entre 2005-2015, o número total de crianças imigrantes subiu 21\%. Os dados apontam que 31 milhões de crianças vivem fora do seu país de nascimento, incluindo 11 milhões de refugiados infantis e requerentes de asilo. Quase uma em cada três crianças é um refugiado; para os adultos, a proporção segundo o ACNUR é menor, de 1 em 20.

A Turquia acolhe o maior número de refugiados recentes, e muito provavelmente o maior número de crianças refugiadas do mundo. Em relação à sua população, o Líbano acolhe o maior 
número por uma margem esmagadora: aproximadamente 1 em cada 5 pessoas. Contudo, considerando os países de acolhimento de acordo com o nível de rendimento, é na República Democrática do Congo, na Etiópia e no Paquistão que se registra a maior concentração.

$\mathrm{O}$ relatório $A$ Child is a Child: protecting children on the move from violence, abuse and exploitation ${ }^{7}$ - UNICEF (2017) identificou que entre 2015-2016, 300 mil crianças e adolescentes não acompanhados e separados, que se deslocavam entre as fronteiras de cerca de 80 países - quase cinco vezes mais do que entre 2010-2011, com cerca de 66 mil. Segundo a UNICEF, muitas dessas crianças estão particularmente em risco de abuso e detenção, porque não têm documentos, porque têm um estatuto legal incerto e por falta de acompanhamento e monitorização sistemáticas do seu bem-estar, por isso, acabam caindo nas lacunas do sistema.

Há muitas razões que levam essas crianças/adolescentes a lançarem-se nestas jornadas sozinhas, que incluem desde a desestruturação familiar, violência doméstica, casamento precoce, recrutamento forçado, até aquelas que procuram juntar-se às suas famílias e parentes que já vivem em outros países, tentando realizar os anseios de seus familiares, que aspiram uma vida melhor para a geração atual.

As percepções sobre os eventuais benefícios, em especial a determinados destinos mais cobiçados, são muito disseminadas através das redes sociais e surgem do imaginário coletivo através de histórias e narrativas contadas por migrantes retornados e não migrantes, reproduzindo crenças e experiências de sucesso e de alcance de objetivos que parecem muito mais acessíveis do que no país de origem.

De acordo com comunicado da UNICEF (2016b), a Interpol estima que 1 em cada 9 crianças refugiadas e migrantes desacompanhadas não estão contabilizadas ou o seu paradeiro é desconhecido, contudo, acredita-se que o número real seja muito maior. Na Eslovénia, por exemplo, mais de $80 \%$ desaparecem dos centros de recepção, enquanto na Suécia o percentual gira em torno de 10\% por semana. Muitas simplesmente fogem dos centros de recepção para juntarem-se mais rapidamente às suas famílias, devido à falta de explicações sobre seus direitos e a possibilidade de serem devidamente ouvidas.

Um documento relevante produzido pela American Civil Liberties Union ${ }^{8}$ (ACLU, 2018) e pela International Human Rights Clinic ${ }^{9}$ da University of Chicago Law School ${ }^{10}$, divulgado num artigo do Chicago Tribune, denuncia que, entre 2009-2014, foram cometidos diversos abusos por funcionários do Department of Homeland Security's Customs and Border Protection ${ }^{11}$ dos Estados Unidos contra crianças e adolescentes não documentados. O relatório intitulado We must protect migrant children from abuse by U.S. Border Patrol ${ }^{12}$, é baseado na leitura jurídica de aproximadamente 300 mil páginas de processos obtidos pela ACLU no período de 5 anos.

O relatório afirma que crianças e adolescentes indocumentados, na época sob custódia da U.S. Border Patrol ${ }^{13}$, relataram casos de humilhação e sessões de espancamento e tortura promovidas por autoridades policiais. Além de outros relatos de abuso e violação dos direitos humanos, como o de privação de alimentos, falta de atendimento médico e hospitalar, além de precárias condições dos alojamentos, com falta de colchões, cobertores, produtos de higiene e limpeza. Predominam nacionalidades vindas de países da América Central, como Honduras, Guatemala e El Salvador, entre 9 e 16 anos, com o objetivo de reencontrar familiares próximos nos Estados Unidos - em geral, o pai ou a mãe -, ou então, fugindo das ações violentas e de ameaças à vida promovidas

\footnotetext{
7 Criança é criança: protegendo as crianças da violência, abuso e exploração.

8 União Americana das Liberdades Civis.

9 Clínica Internacional de Direitos Humanos.

10 Escola de Direito da Universidade de Chicago.

11 Departamento de Alfândega de Segurança Interna e Proteção de Fronteiras.

12 Devemos proteger as crianças migrantes do abuso da Patrulha de Fronteira dos EUA.

13 Patrulha Fronteiriça dos Estados Unidos.
} 
por grupos pandilleros (gangues), pelo crime organizado, ou pelos próprios familiares em seus respectivos países.

Muitas viajam sozinhas ou em grupos pequenos cruzando o território do México em composições ferroviárias de carga, conhecidas como La Bestia. Além dos riscos de acidentes, quase sempre resultando em mortes ou mutilações, e dos constantes assaltos, também perpetrados por transmigrantes ${ }^{14}$ adultos, uma vez em território mexicano são presas fáceis para grupos de narcotraficantes, sequestradores, exploradores sexuais e autoridades policiais inescrupulosas. Não são raros os casos de meninas e meninos transmigrantes raptados a fim de abastecer o mercado da prostituição infantil.

O documento também demonstrou grande preocupação a respeito da piora na situação desse grupo a partir do governo do ex-presidente Donald Trump, e tinha razão nesta preocupação, pois em junho de 2018 alguns jornalistas da Agência ProPublica denunciaram a situação precária, devido a uma política instalada de "Tolerância Zero" aos imigrantes.

Desde que o ex-presidente americano implementou uma política de combate total à imigração, milhares de crianças latino-americanas foram separadas dos seus pais e enjauladas em uma espécie de campo de concentração. Durante vários dias de 2018, foram proibidas as visitas de jornalistas ao local para averiguação das condições em que vinham sendo mantidas. As crianças ficaram em completo isolamento, sujeitas aos diversos abusos das autoridades fronteiriças, sem que ninguém pudesse intervir.

A agência de jornalismo investigativo ProPublica (EL PAÍS, 2018) obteve uma gravação de áudio feita no interior de uma instalação da Patrulha Fronteiriça, que captou em meio ao choro generalizado, um agente zombar do desespero das crianças dizendo: "[...] temos uma orquestra por aqui. Só falta o maestro", enquanto uma menina salvadorenha de 6 anos, aos prantos, implorava para que ligassem para a sua tia ir resgatá-la. Segundo informações da agência, mais de 100 crianças tinham menos de 4 anos.

Várias entidades e associações se manifestaram na época, entre elas a Associação de Pediatras norte-americana que considerou o fato como "prática cruel" e um abuso contra crianças consentido pelo Governo, que pode causar "danos irreparáveis" com "consequências para toda a vida" para os menores: "[...] Pensar que um Estado pretende dissuadir os pais (de entrar ilegalmente no país) ao infligir tal abuso sobre as crianças é inadmissível”.

Ao invés de recuar diante das denúncias internacionais e nacionais, o ex-presidente americano chamou de "piores criminosos do mundo" os pais das crianças, que são levados a presídios federais (podendo ficar presos por anos), por buscarem em outro país melhores condições de vida para os seus filhos.

O Governo dos Estados Unidos, pelo menos durante o Governo de Donald Trump, permaneceu indiferente às manifestações de diversas organizações de direitos humanos, demonstrando isso através de sua saída do Conselho dos Direitos Humanos da Organização das Nações Unidas - ONU -. Importante destacar que tais políticas contaram com o forte apoio de uma parte da população americana, que endossa as políticas restritivas instauradas pelo governo quanto à imigração no país. Cabe observar que tomou posse em janeiro de 2020 o novo presidente americano, Joe Biden, e se espera que ele reverta tal situação, mas nos cabe aguardar quais serão suas medidas. 


\section{Os desafios enfrentados diante do acesso à educação}

Além das questões já mencionadas anteriormente sobre as condições que crianças/ adolescentes migrantes enfrentam pelo mundo (desacompanhadas, desaparecidas, sequestradas, exploradas, sem paradeiro certo, ou mortas em travessias perigosas), destaca-se um dos principais fatores que envolve a motivação pela qual muitas famílias optam pela migração: a busca de uma vida melhor para os filhos, que passa certamente por dar-lhes uma educação formal digna. Porém, esse sonho pode, por muitas vezes, se tornar um pesadelo, devido às dificuldades enfrentadas para o acesso à educação nos países de acolhimento.

O direito à educação e o princípio da não discriminação estão consagrados na Convenção sobre os Direitos da Criança, ratificado em 1990, e também em diversos outros instrumentos de proteção à infância aprovados em Assembleia Geral das Nações Unidas. Contudo, na prática, as políticas restritivas de imigração, leis inconsistentes e exigências rigorosas de documentação nos países receptores podem impedir a realização desse direito.

Um ordenamento jurídico inclusivo não necessariamente impede práticas discriminatórias regionais ou locais, pois a falta de documentação se configura como um entrave para realização das matrículas. As escolas podem exigir certidões de nascimento, histórico escolar anterior, documentos de identificação nacional ou comprovantes de residência. De acordo com o relatório da Organização das Nações Unidas para a Educação, a Ciência e a Cultura - UNESCO (2018), no Chipre e na Eslováquia, as escolas são obrigadas a reportar às autoridades imigratórias, as famílias sem documentação válida, o que representa uma ameaça de deportação ${ }^{15}$ que pode impedir as crianças de frequentarem a escola. Na África do Sul, a Lei de Imigração de 2002 impede que migrantes sem documentos se matriculem na escola. No Chile, onde o número de migrantes haitianos aumentou de menos de 5 mil, em 2010, para 105 mil, em 2017, as políticas determinam que a educação pública deve ser ofertada a todas as crianças; na prática, a oferta educacional depende de funcionários do governo local.

No Brasil a garantia de acesso à educação está presente na Constituição Federal de 1988 (artigos $5^{\circ}$ e 6 $6^{\circ}$ ), no Estatuto da Criança e Adolescente (Lei 8.069/1990), Lei de Diretrizes e Bases da Educação Nacional (Lei 9.393/1996), Lei dos Refugiados (Lei 9.474/1997) e na Lei da Migração (Lei 13.445/2017), entre outros decretos municipais e estaduais. Contudo, a falta de documentação, a burocracia e a desinformação sobre os direitos relativos a essa população se tornam muitas vezes, impeditivos para o acesso à escola no país.

Desta forma, apesar de tantas garantias presentes em leis nacionais e internacionais de proteção aos imigrantes, um dos maiores desafios enfrentados por esse grupo é a igualdade de condições para o acesso e permanência nas instituições de ensino. Essa situação faz com que os potenciais benefícios da migração, como a "educação", sejam perdidos diante de tantos obstáculos.

\section{O processo de adaptação através da escola}

Ultrapassados os entraves de acesso à educação, a entrada na escola, surge como desafiadora nesse processo conturbado de adaptação ${ }^{16}$ no novo país. Um grande desafio para as crianças e adolescentes que estão em idade escolar, que imigram acompanhando sua família, é que precisam

15 Deportação consiste num dos modos de devolução do estrangeiro ao exterior que pode decorrer da prática de delito, ou do não cumprimento dos requisitos para entrar ou permanecer em território nacional.

16 Adaptação, como se refere Guy Rocher, "a adaptação de uma pessoa ao seu ambiente significa que essa pessoa interiorizou os modelos, os valores e os símbolos do seu meio, que os integrou na estrutura da sua personalidade para mais facilmente comunicar e comungar com os membros das coletividades em que participa" (ROCHER, 1989, p. 115). 
adaptar-se muito rapidamente a esse novo lugar, ou seja, mais que seus pais ou familiares, elas precisam incorporar os costumes e as regras sociais para que sejam integradas rapidamente a um novo e diferente modelo de vida e sistema de ensino e, na maioria das vezes, aprender um novo idioma simultaneamente. Assim, a infância que é a época das descobertas do mundo, torna-se amedrontadora, à medida que são expostas a desafios além de sua compreensão e de sua capacidade de resolvê-los sozinhas ou com pouco apoio (FABIANO; BÓGUS; PASTERNAK, 2019).

Segundo a ACNUR (UNHCR, 2019), uma criança refugiada tem 5 vezes mais probabilidade de não frequentar a escola do que uma criança não refugiada. E quando tem a oportunidade de frequentar a escola, esse é justamente o local onde é maior a probabilidade destas crianças serem alvo de vários tipos de discriminação, incluindo tratamento desigual e bullying. Fora da sala de aula, as barreiras legais impedem as crianças imigrantes de se beneficiarem de serviços em pé de igualdade com as crianças naturais do país em questão. Nos casos mais graves, a xenofobia ${ }^{17}$ pode subir de tom e chegar a ataques diretos.

Um estudo realizado pela OCDE - Organização para a Cooperação e Desenvolvimento Econômico (2018), intitulado The Resilience of Students with an Immigrant Background: Factors that Shape Well-Being ${ }^{18}$, mostrou que as desvantagens socioeconômicas e as barreiras linguísticas são os maiores obstáculos ao sucesso na escola para estudantes de famílias de imigrantes. Outra constatação importante de acordo com a pesquisa é que cerca de $50 \%$ dos alunos de origem estrangeira não conseguiram atingir as habilidades acadêmicas básicas em leitura, matemática e ciências. Entre os alunos nativos, ou seja, os que não têm origem estrangeira, a proporção é de um em cada quatro.

O relatório também mostrou que estudantes estrangeiros sentiam um menor senso de pertencimento na escola do que os estudantes nativos, além de relatarem ter menos satisfação e maior ansiedade relacionada com as atividades escolares. No entanto, muitos expressaram altos níveis de motivação para alcançar um melhor desempenho. Também são mais propensos a frequentar escolas com um pior clima disciplinar e uma maior prevalência de faltas. A língua também é determinante, pois os alunos que não falam a língua do país em suas próprias casas têm resultados piores no teste realizado pelo Programa Internacional de Avaliação de Estudantes - PISA, do que os estudantes imigrantes que já falam a língua nativa.

Segundo Daure, Reyverand-Coulon e Forzan (2014), as primeiras impressões que o imigrante tem em relação ao país de acolhimento é que nada lhe parece familiar e a perda das referências, como, por exemplo, a língua, os espaços, os odores e os sabores, é acompanhada de um sentimento de insegurança que pode ser muitas vezes, de rejeição, que causam desconforto e stress. No caso das crianças e dos adolescentes, isso se dá de uma maneira ainda mais acentuada, devido à fase da vida em que estão e a todos os sentimentos e mudanças a que estão expostos.

Portanto, o sentimento de acolhimento e de aceitação é evidentemente indispensável para que a criança/adolescente imigrante possa afirmar o seu pertencimento cultural e vivê-lo como valor a colocar em evidência na relação social e no encontro com o outro (DAURE; REYVERAND-COULON; FORZAN, 2014). Ao contrário, a rejeição e o sentimento de exclusão podem levá-lo a um sentimento de insegurança sobre as suas competências culturais e a uma desvalorização de suas origens em detrimento da cultura do país que o acolheu.

Ramos (2007) salienta que no período das grandes aprendizagens escolares (6-10 anos) da leitura, escrita e cálculo em que a criança se encontra disponível para novas aprendizagens e novos conhecimentos escolares, ela é obrigada a separar-se do espaço familiar, do mundo da intimidade e da língua materna, para se inscrever num espaço escolar, num mundo e numa língua estrangeira.

17 Xenofobia de acordo com o ACNUR são atitudes, preconceitos e comportamentos que rejeitam, excluem e frequentemente difamam pessoas, com base na percepção de que eles são estranhos ou estrangeiros à comunidade, sociedade ou identidade nacional. 18 A resiliência de estudantes de origem migrante: fatores que moldam o bem-estar. 
Já a adolescência (11-18 anos) é caracterizada por um período de grandes transformações psicofisiológicas e identitária, de rupturas múltiplas (com a família, cultura, sociedade) e de maturação (ao nível da autoafirmação, da conquista de autonomia e da adaptação sexual).

Portanto, é necessário, neste período, uma maior abertura da escola às realidades familiares, sociais e culturais, que seja acompanhada da valorização de sua língua materna e da cultura familiar, de forma a permitir a construção de autoestima e aprendizagens, que minimizarão a clivagem ${ }^{19}$ entre os universos de pertença da criança, prevenindo os disfuncionamentos cognitivos, linguísticos e psíquicos futuros.

Para Ramos (2007), a estruturação psíquica e cultural da criança migrante é construída sobre clivagens e este é um fator determinante de vulnerabilidade. A clivagem entre a cultura de origem e a cultura de acolhimento, entre o mundo de dentro e o mundo de fora e o rápido controle de um universo duplo, dão uma ilusão de independência em relação às regras comuns, colocando em certos casos, problemas de identidade, sentimentos de desvalorização e insegurança, dificuldades psicológicas e de integração social, fatores que isolados ou conjugados poderão refletir-se na adaptação social e escolar e no próprio rendimento escolar.

Franzé (1999), em seus estudos, chama a nossa atenção para outra face da situação escolar de estudantes de origem estrangeira que frequentemente é relegada a um plano de fundo da análise, coloca que muitos dos obstáculos educacionais e socioafetivos encontrados por esse grupo, vão muito além da questão da "origem". No entanto, a autora destaca que predomina um discurso que tende a relacionar as dificuldades de integração com a diversidade étnico-cultural. A questão da diversidade é muito mais ampla e também está vinculada às habilidades, aos conhecimentos e aos saberes que não são apenas locais ou étnicos, mas abrange todos os alunos da escola. Franzé (1999) ainda destaca que talvez o que esteja acontecendo é que tendemos a perceber as dificuldades de adaptação/integração como resultado de uma diferença cultural, correndo o risco de confundir desigualdades sociais, jurídicas, de acesso aos recursos e escolares, com a diversidade.

\section{Discriminação e preconceito}

Sabe-se que os fluxos migratórios criam, muitas vezes, nos governantes e na população uma série de inquietações. Os imigrantes são vistos, muitas vezes, como ameaça ao mercado de trabalho, no uso dos serviços públicos e como responsáveis pelo aumento da violência. Com esta visão distorcida, os governos e, em muitos casos, a própria sociedade tornam-se cada vez mais resistentes à entrada de estrangeiros e adotam como solução o estabelecimento de maiores restrições e impedimentos legais, na tentativa de "equacionar" a questão migratória vista como problema (BÓGUS; FABIANO, 2016).

Quando se analisa especificamente a população migrante no ambiente escolar, verifica-se as mesmas posturas preconceituosas e estigmatizantes. O preconceito e a discriminação que estão expostos são normalmente associados a seus atributos físicos, linguísticos e socioculturais como: maneira de falar, sotaque, aparência física, características étnicas, práticas culturais, condições socioeconômicas, entre outras questões.

A constante exposição dos estudantes estrangeiros a esta situação, gera, de acordo com Goffman (2006), "identidades degeneradas", pois evidencia atributos que não estão em harmonia com as identidades destes indivíduos, mas que pelo contrário são criados e usados para estereo-

19 Clivagem é um mecanismo de defesa psicológico que se traduz na separação radical entre dois polos opostos de afetos, sentimentos, sobre um mesmo objeto e que não podem se correlacionar ao mesmo tempo. O conceito de clivagem foi introduzido por Sigmund Freud (1856-1939), em 1927, em o Futuro de uma Ilusão. Este autor explica que no ego existem duas atitudes opostas: uma nega a realidade e outra aceita. 
tipá-los, caracterizando o processo de estigmatização. Ainda segundo o autor esse processo não ocorre somente em razão da existência de um atributo em si, mas da existência de uma relação incongruente, entre os atributos e os estereótipos que os membros da sociedade criam para determinado tipo de pessoa.

Neste sentido, Ianni (1996, p. 19) cita que há algo de muito particular e simultaneamente de muito geral que faz com que as marcas raciais, ou fenotípicas, sejam reelaboradas socialmente como estigmas, consubstanciando e alimentando a xenofobia, o etnicismo, o preconceito ou o racismo. E argumenta que este pode ser o núcleo da questão: a metamorfose da marca em estigma que é elaborada e reelaborada socialmente, tanto em termos de senso comum como de conhecimento que se propõe científico.

A característica principal atribuída ao "outro", ou seja, ao "diferente", é a de descrédito social, que, segundo Goffman (2006), fazem surgir outros juízos de valor atribuídos a esse indivíduo. Os insultos, chacotas e brigas podem, então, produzir consequências danosas para a construção da autoestima e das identidades destas crianças e adolescentes.

Para Cummins (1996), grande parte dos estudantes culturalmente diversos que fracassam academicamente sofrem ou já sofreram algum tipo de discriminação ou estigma na escola. Isso ocorre justamente porque internalizam um senso de ambivalência e insegurança em razão da rejeição sofrida e da resistência por parte do grupo dominante, no caso aqui, especialmente os colegas, mas também os próprios educadores e o restante dos sujeitos que fazem parte do ambiente escolar.

Portanto, a escola se torna um ator que se destaca nesse processo, sendo oportuno enfatizar que a função social da escola ultrapassa a simples transmissão de conhecimento sistemático e se destaca como um importante espaço de convivência humana entre os mais variados grupos e diversas culturas.

Desta forma, é necessário assinalar que é por intermédio da criação de contextos educativos pautados num olhar criterioso aos fenômenos sociais que as transformações educacionais podem operar no sentido de encontrar soluções e ferramentas que possam auxiliar os estudantes imigrantes, e tantos outros que também sofrem com estigmas, discriminações e preconceitos, envolvendo a todos que fazem parte desse ambiente na busca da conscientização e da empatia dentro e fora do ambiente escolar.

\section{Considerações Finais}

As migrações contemporâneas neste século se desenvolvem em meio a discrepâncias nos níveis de renda entre países ricos e pobres, que intensificam a pobreza e os conflitos existentes nos países, fazendo com que milhões de pessoas se desloquem em busca de uma vida melhor.

Diante desse quadro que se apresenta, a migração infantil desponta como um dos aspectos mais desafiadores nesse contexto, escancarando a vulnerabilidade a que crianças e adolescentes estão sujeitos. Pois, mesmo após acolhidos nos países de destino, enfrentam vários obstáculos que vão desde a dificuldade de acesso à educação, até o conturbado processo de adaptação marcado por discriminações e preconceitos em razão de sua origem, etnia e condições socioeconômicas, que por muitas vezes, os levam a abandonarem a escola e a desenvolverem doenças como stress, quadros de depressão e até mesmo de agressividade.

Apesar dessa questão ser pauta urgente e ter várias facetas, nada ou quase nada tem sido feito pelas autoridades políticas dos países envolvidos para que essa tragédia humanitária do século XXI seja estancada. Neste sentido, constata-se a necessidade de políticas públicas mais eficazes nos países de acolhimento e principalmente de uma mudança radical no olhar dos governantes sobre as peculiaridades dos movimentos migratórios e dos atores envolvidos nesse processo. Sendo assim, estudos e pesquisas que colaborem para a melhoria na atual situação são indispensáveis para nortear as políticas públicas na busca de soluções viáveis e concretas. 


\section{Referências}

AMERICAN CIVIL LIBERTIES UNION (ACLU). We must protect migrant children from abuse by U.S. Border Patrol. University of Chicago Law School. Chicago Tribune, Chicago, 24 maio 2018. Disponível em: http://www.chicagotribune. com/news/opinion/commentary/ct-perspec-children-abused-immigrants-rights-0525-20180523-story.html. Acesso em: 24 jul. 2019.

BAENINGER, Rosana. Migrações internacionais: elementos para o debate no século XXI. In: CUTTI, Dirceu et al. (org.) Migração, trabalho e cidadania. São Paulo: EDUC, 2015. p. 14-26.

BAENINGER, Rosana; FERNANDES, Duval, et al. (org.) Atlas Temático: Observatório das Migrações em São Paulo - Migrações Internacionais. Campinas: NEPO: UNICAMP, 2018.

BAKEWELL, Oliver. Some reflections on structure and agency in migration theory. Journal of Ethnic \& Migration Studies, Reino Unido, v. 36, n. 10, 2010.

BÓGUS, Lucia Maria Machado; FABIANO, Maria Lucia Alves. O Brasil como destino das migrações internacionais recentes: novas relações, possibilidades e desafios. In: SIQUEIRA, Maria da Penha Smarzaro; ROSA, Teresa Cristina da Silva. Questões Contemporâneas. Florianópolis: Insular, 2016. v. 1: Coleção Debate social. p. 141-160.

CASTLES, Stephen. Globalización y migración: algunas contradicciones urgentes. Texto del discurso inaugural presentado en la reunión del Consejo Intergubernamental del MOST, 16 de junio de 1997. [S. l.: s. n.], 1997.

CASTLES, Stephen. Entendendo a migração global. Uma perspectiva desde a transformação social. Revista Interdisciplinar da Mobilidade Humana, Brasília, DF, ano 18, n. 35, p. 11-43, jul./dez. 2010.

CUMMINS, Jim. Negotiating identities: Education for empowerment in a diverse society. Ontario: California Association for Bilingual Education, 1996.

DAURE, Ivy; REYVERAND-COULON, Odile; FORZAN, Sabine. Relações familiares e migração: um modelo teórico-clínico em psicologia. Revista PEPSIC - Psicologia clínica, Rio de janeiro, v. 26, n. 1, p. 91-108, jun. 2014. Disponível em: http://pepsic.bvsalud.org/scielo.php?script=sci_arttext\&pid=S0103-56652014000100007. Acesso em: 04 abr. 2019.

GINGER, Thompson (ProPublica). O choro desesperado das crianças separadas dos seus pais na fronteira dos Estados Unidos. EL PAÍS, Washington, 19 jun. 2018. Disponível em: https://brasil.elpais.com/brasil/2018/06/19/actualidad/1529416024_598528.html. Acesso em: 15 dez. 2020.

FABIANO, Maria Lucia Alves; BÓGUS, Lucia Maria Machado; PASTERNAK, Suzana. Educação e inclusão social: desafios e dilemas enfrentados pelas crianças imigrantes no Brasil. Revista Temas de Antropología y Migración, Buenos Aires, n. 11, dez. 2019.

FRANZÉ, Adela. Escolarización de niños de origen marroquí y educación intercultural: algunas reflexiones sobre el caso español. Anales de Historia Contemporánea, Espanha, n. 15, 1999.

GOFFMAN, Erving. Estigma: notas sobre a manipulação da identidade deteriorada. Trad. Mathias Lambert. Rio de Janeiro: Livros Técnicos e Científicos, 2006.

IANNI, Octávio. A racialização do mundo. Revista Tempo Social, São Paulo, v. 8, n. 1, p. 1-23, maio 1996.

INTERNATIONAL ORGANIZATION FOR MIGRATION (IOM). Fatal Journeys: Improving Data on Missing Migrants. V. 3, part I. Geneva: IOM's: GMDAC, 2017.

ORGANIZAÇÃO PARA COOPERAÇÃO E DESENVOLVIMENTO ECONÔMICO (OCDE). The resilience of students with an immigrant background - factors that shape well being. Paris: OECD Publishing, 2018. Disponível em: http:// dx.doi.org/101787/9789264292093-en. Acesso em: 24 mar. 2018.

PATARRA, Neide Lopes. Migrações internacionais: teorias, políticas e movimentos sociais. Revista Estudos Avançados, São Paulo, v. 20, n. 57, maio/ago. 2006.

RAMOS, Natália. Interculturalidade, educação e desenvolvimento - o caso das crianças migrantes. In: BIZARRO, Rosa (org.). Eu e o outro: estudos multidisciplinares sobre identidade(s), diversidade(s) e práticas culturais. Lisboa: Areal Editores, 2007. p. 367-375.

ROCHER, Guy. Sociologia geral: a acção social. Lisboa: Editorial Presença, 1989. V. 1.

THE UN REFUGEE AGENCY (UNHCR). Desperate Journeys: refugees and migrants arriving in Europe and Europe's borders. Genebra: UNHCR, 2019. 
UNESCO. Relatório de Monitoramento Global da Educação 2019: migração, deslocamento e educação: construir pontes, não muros, resumo. Brasília, DF: UNESCO, 2018.

UNITED NATIONS CHILDREN'S FUND (UNICEF). Uprooted: The growing crisis for refugee and migrant children. New York: UNICEF, 2016a.

UNITED NATIONS CHILDREN'S FUND (UNICEF). Comunicado à imprensa: Crianças refugiadas e migrantes não acompanhadas precisam urgentemente de proteção. Genebra: UNICEF, $2016 \mathrm{~b}$.

UNITED NATIONS CHILDREN'S FUND (UNICEF). A child is a child: protecting children on the move from violence, abuse and exploitation. New York: UNICEF, 2017.

UNITED NATIONS (ONU). Department of Economic and Social Affairs. Population Division. Trends in International Migrant Stock: The 2017 revision. [S. l.]: POP: DB: MIG: Stock: Rev., 2017.

US BORDER PATROL. U.S. Border Patrol Fiscal Year Southwest Border Sector Deaths (FY 1998 - FY 2016). Estados Unidos: US Border Patrol, July 2017.

Data de submissão: 01/02/2021

Data de aceite: 10/03/2021 